\title{
Algumas considerações a condução da Política Monetária do Novo Consenso Macroeconômico a luz da visão keynesiana
}

\author{
Some considerations on Monetary Politics condution of the New \\ Macroeconomic Consensus under a keyniasian view
}

Paulo Jose Saraiva ${ }^{\mathrm{I}}$

\begin{abstract}
RESUMO
Neste artigo são abordados, brevemente, os principais elementos teóricos do Novo Consenso Macroeconômico pré e pós crise américa de 2007. Como contraponto, se apresenta a visão pós keynesiana, bem como as implicações desta para a condução da política monetária. Para tanto, são debatidos os objetivos e instrumentos da política monetária, no que se refere ao papel desempenhado pelos bancos e pelas firmas não bancárias no mecanismo de transmissão da política monetária, além de suas implicações em relação ao investimento e o crescimento econômico. Por fim, são elencadas as críticas keynesianas a visão tradicional.
\end{abstract}

Palavras-chaves: Teoria Pós-keynesiana; Teoria monetária da produção; política monetária; Mecanismo de transmissão e inflação

\begin{abstract}
This article briefy discusses the main theoretical elements of the New Macroeconomic Consensus before and after the crisis of 2007. As a counterpoint, the post-Keynesian view is presented, as well as its implications for the conduct of monetary policy. To that end, the objectives and instruments of monetary policy are debated, regarding the role played by banks and non-baking firms in the transmission mechanism of monetary policy, in critiques of the traditional view are listed.
\end{abstract}

Key Words: Post-Keynesian theory; Monetary theory of production; Monetary politics; Transmission mechanism and inflation 


\section{INTRODUÇÃO}

A crise financeira de 2007-2008 e a Grande Recessão que a seguiu reacenderam um antigo debate, moldado a partir da crise de 1929, relativo às críticas de Keynes a visão clássica. Naquela época, a teoria proposta pelo autor, e alterada pela chamada "síntese neoclássica", promoveu a ascensão do programa de pesquisa keynesiano em detrimento da visão clássica pré-crise. Contudo, a hegemonia do modelo IS/LM no pós segunda guerra perdeu espaço a partir da década de 1970, particularmente pela ocorrência da estagflação, observada nos países desenvolvidos. Tal fato, foi um dos elementos que tornou os debates teóricos novamente tendenciosos a visão clássica, retomado pelo programa de pesquisa monetarista e ampliado pelos novos-clássicos, ciclo reais de negócios, novos-keynesianos e mais recentemente pelo Novo Consenso Macroeconômico (NCM). Estes determinaram de forma quase que hegemônica as últimas quatro décadas de pensamento e política econômica nas principais economias mundiais.

Resultado direto destas mudanças, o NCM representa um conjunto extenso e interligado de questões teóricas, estudos empíricos e de experiências práticas de diversos Bancos Centrais (BC), em diversos países desenvolvidos e em desenvolvimento. A busca por uma nova síntese, gerou um papel residual e subordinado às políticas fiscal e financeira em detrimento da política monetária (PM), reafirmação da neutralidade da moeda no longo prazo, a incorporação de expectativas racionais, aceitação da crítica de Lucas, reafirmação da hipótese de mercados eficientes, além da incorporação de modelos dinâmicos de equilíbrio geral estocásticos (DSGE). No entanto, mercados de concorrência imperfeita e friç̧ões de preços e salários foram adicionados ao corpo teórico, assim como a regra de Taylor substituiu a função de equilíbrio do mercado monetário (LM), tornando-se um importante instrumento da PM, conjuntamente com a gestão das expectativas.

Um dos principais produtos desta síntese foi a consolidação do Regime de Metas de Inflação (RMI), implantado por meio de mudanças institucionais e operacionais na condução da PM, a partir do início dos anos noventa. MISHKIN (2007) chegou a afirmar que se estava construindo uma "ciência monetária", enquanto BERNANKE (2004) atribuiu a esta estabilidade econômica (inflação e desemprego) das últimas décadas o qual denominou de "a grande moderação".

No entanto, o aparente sucesso atribuído ao RMI pela "grande moderação" foi interrompido pela crise americana iniciada em 2007 e agonizado a partir do segundo semestre de 2008. Este episódio demonstrou que durante um período de aparente estabilidade, emergia um processo de ampliação da alavancagem e do nível de exposição ao risco no mercado financeiro americano. Na contramão da calmaria vinha se desenvolvendo um movimento especulativo nos mercados financeiros americanos, particularmente nos mercados de hipoteca, cuja inter-relação com os demais mercados gerou uma crise sistêmica e internacional. Como resultado imediato, medidas não convencionais de políticas monetárias (PMNC) foram necessárias e implantadas em grande magnitude para amenizar e reverter os impactos da ruptura financeira e da recessão na atividade economia. Como consequência, emergiram críticas dentro (revisão do NCM) e fora do mainstream econômico sobre a condução da política monetária.

Nesta perspectiva, o artigo articula uma visão alternativa ao NCM, ou seja, uma crítica externa. Para tanto, o ponto de partida é a visão estilizada do RMI, incluindo as políticas monetárias não convencionais. Na segunda parte, discutisse a teoria keynesiana, elencando os seus fundamentos e bases teóricas, cujas implicações para a condução das políticas econômicas de um modo geral e a PM de forma mais específica, contrapõem-se 
fortemente as proposições e orientações do NCM pré e pós crise financeira americana. Na última parte, as considerações finais destacam as principais críticas da teoria monetária da produção a condução da política monetária convencional guiada pelo regime de metas inflação.

\section{UMA VISÃO ESTILIZADA DA CONDUÇÃO DA POLÍTICA MONETÁRIA NO NOVO CONSENSO}

O NCM ${ }^{1}$ é um construto teórico e metodológico da escola novo-keynesiano que se propôs a criar uma "ciência monetária" a partir de elementos de diversas concepções teóricas, como os monetaristas, novos clássicos, ciclos reais de negócios, além de seus próprios desenvolvimentos. O produto resultante desta síntese foi implantado por meio de mudanças institucionais e operacionais na condução da PMC, através da definição do objetivo primordial do banco central (BC) de promoção da estabilidade de preços, tendo para tanto adquirido a autonomia operacional para perseguir tal objetivo.

Em termos operacionais a regra de Taylor sintetiza esta mudança, na qual a inflação é definida como a âncora nominal da PMC, uma vez que tanto a taxa natural de desemprego, quanto à taxa de juros de equilíbrio não são passiveis de determinação (Davidson, 2006). Ademais, o fim do regime de câmbio fixo no início da década de 1970 (Bretton Woods) e as limitações encontradas na adoção de metas monetárias na década de oitenta, em virtude das inovações financeiras e das variações não previsíveis na velocidade de circulação da moeda, impuserem sérias restrições à condução da política monetária com base em regras monetárias.

A partir da nova regra de condução PMC, a manipulação da taxa de juros de curto prazo e a comunicação com o público são definidas como os instrumentos operacionais e convencionais da PM. Estas são alteradas, quando necessário, para afetar as metas intermediárias - taxa de juros de longo prazo e as expectativas de inflação - e deste modo à demanda no curto prazo, dado que no longo prazo a PM é neutra, tendo como objetivo final uma inflação baixa e estável. Esta configuração de PMC é denominada de "regime de metas de inflação".

Ressalta-se, que embora tenham sido enfatizados outros canais pelos quais a PMC é transmitida a demanda agregada, como exposto por Bernanke e Getler (1995), os mecanismos de transmissão foram simplificados aos impactos da taxa de juros de curto prazo sobre as expectativas de inflação e as taxas de juros reais longas e, deste modo, sobre a substituição intertemporal dos agentes (consumo presente ou futuro), de modo similar ao modelo padrão IS/LM, porém incorporando o canal de expectativas. Nesta nova configuração de PMC, os canais de crédito amplo e restrito, além da taxa de câmbio, não foram ignorados, mas supõe-se que estes se moveriam de forma previsível e estável as mudanças na taxa básica de juros (Meyer, 2001; Goodfriend, 2005). Essa simplificação representa a "doutrina Greenspan"2 e a aceitação da hipótese de mercados eficientes pelo

1. A seguir são apresentados alguns autores e publicações que defendem a existência de um núcleo comum e convergente de pesquisas em macroeconomia pré-crise: Blanchard (1997), Blinder (1997), Taylor (1997), Bernanke (2004), Meyer (2001), MacCallum (2002), Goodfriend (2007) e Woodford (2009).

2. De um modo geral a "doutrina Greenspan" defendia a atuação do BC após a ruptura da bolha (para "limpar"), ao invés da atuação preventiva "inclinar-se contra o vento". 
NCM (Bernanke e Getler, 1999 e 2001), além da irrelevância da manipulação da oferta monetária como variável operacional da PM.

Como resultado desta simplificação, o modelo teórico do NCM suprimiu a equação do mercado monetário (LM), substituindo-a pela regra de Taylor. A principal implicação deste modelo é de que a moeda não importa e deste modo, em tese, a PMNC, particularmente as compras de ativos, não teriam nenhum impacto sobre a atividade econômica, pois a taxa de juros de longo prazo e as expectativas dependem da taxa de juros de curto prazo, além da comunicação que está sujeita à credibilidade de um BC. A única alternativa para uma situação na qual a PMC perde a sua efetividade (i.e, quando a taxa de juros de curto prazo está próxima a zero3) é a "forward policy guidance", informando aos agentes sobre as intenções futuras desta (Eggertsson e Woodford, 2003).

O NCM limitou o escopo de atuação da política monetária. Sua operacionalização foi circunscrita ao uso das operações de mercado aberto - que se tornou o principal instrumento da PM - e ao gerenciamento das expectativas dos agentes econômicos. Assim, conferiu-se um papel secundário aos demais instrumentos de política monetária, com destaque para o fato de que o recolhimento de depósitos compulsórios foi virtualmente abolido na maioria dos países desenvolvidos, no período anterior à crise.

Ressalta-se que o Fed, até o período pré-2008, manteve um percentual de exigência de reservas mínimas ${ }^{4}$ (compulsório). Este foi justificado pela necessidade de maior segurança nas operações financeiras, apoiando as transferências de recursos entre as instituições, bem como desempenhava um importante papel na operacionalização da PMC, no sentido (no caso do compulsório) de auxiliar a estabilidade da demanda por reservas bancárias e assim facilitar a ação do BC na fixação da taxa de juros.

Já as operações de redesconto e empréstimo de liquidez funcionam em vários países como uma "válvula de segurança" colocada à disposição dos bancos depositários para solucionar problemas individuais de caixa que venham ocorrer no final do dia ou no final do período de movimento do recolhimento compulsório (Carvalho et al, 2015, cap. 11 e 12).

Contudo, a crise financeira de 2007-2008 trouxe questionamentos ao arcabouço teórico ${ }^{5}$ e deslocando este dos procedimentos operacionais do NCM em relação à factibilidade do "forward policy guidance" em contraponto a efetividade das PMNC. Ressalta-se que estas tiveram um importante papel no reestabelecimento de mercados

3. Quando o mecanismo de transmissão via canal de taxa de juros perde o seu efeito, o BC perde a capacidade de reduzir os spreads de juros de longo prazo, uma vez que não consegue achatar a estrutura a termo da taxa de juros e o prêmio de risco, e desta forma, o $\mathrm{BC}$ perde a capacidade de estimular a demanda agregada e produto. Ademais, os canais de crédito, de câmbio, de preços dos ativos e dos preços relativos deixam de operar via taxa básica, limitando ainda mais a PM.

4. O Fed determina o compulsório sobre o passivo dos bancos, sendo as faixas percentuais de $0 \%$, $3 \%$ e $10 \%$.

5. A crise financeira abalou a estrutura teórica do NCM e vem provocando um debate de revisão (rethinking) na ortodoxia, em especial nos EUA, um movimento em boa medida capitaneado pelo FMI (Blanchard et al, 2010; 2013) e autores neoclássicos mais críticos ao NCM, tais como Einchengreen, Krugman e Stiglitz. Cabe ressaltar que Taylor (2010a, 2010b) reafirma os mesmos preceitos teóricos e orientações de política econômica do NCM, sustentando que a crise foi causada pelo desvirtuamento das políticas convencionais. Minskhin (2010, p.32), por sua vez, afirma: "The arguments supporting central banks' adhering to the principles of the new neoclassical synthesis are still every bit as strong as they were before the crisis". Para uma discussão sobre o debate macroeconômico no mainstream norte-americano pós-crise e se o mesmo representou ou não uma ruptura com o programa de pesquisa do NCM, ver Paula e Saraiva (2015). 
financeiros, além do estímulo a atividade econômica e o emprego. As políticas de crédito 6 nos EUA extrapolaram, em muito,a magnitude da PMC normalmente observada em tempos normais, bem como foram estendidas para instituições não depositárias, ampliando a atuação do $\mathrm{BC}$ no mercado de capitais. Ademais, as políticas de quase débito7 foram as principais ferramentas de estímulo a retomada do crescimento econômico, e de modo contraditório as proposições teóricas do NCM, implicaram nos efeitos da expansão do balanço do Fed e consequentemente representaram um impacto da base monetária sobre as variáveis reais. Cecioni et al (2011, p. 6) definem as PMNC:

We therefore classify as non-standard tools all the measures implemented during the global financial crisis that addressed liquidity shortages both of depository institutions and of other important segments of the financial market, the direct purchase of private and public securities, and the adoption of particular forms of communication designed to restore a more normal functioning of the markets and influence expectations about future official interest rates.

No quadro 1 são apresentados os mecanismos de transmissão da PMNC. Note que as políticas de balanço (crédito e quase débito) se processam por meio da atuação direta do BC nos mercados financeiros (instituições depositárias e não depositárias), através de compra e/ou troca (temporária e/ou definitiva) de títulos. As políticas de crédito operam via os canais amplo e restrito, sem impactar a estrutura a termo da taxa de juros, com o objetivo de se reestabelecer as condições de liquidez, reduzir os prêmios de risco e incentivar a oferta de crédito. Estas medidas têm como referência teórica os trabalhos de Bernanke e Blinder (1989) e Bernanke e Bernanke (1995).

Já as políticas de quase débito, se fundamentam nas formulações originais de Tobin (1969), Ando e Modigliani (1963) e Modigliani e Sutch (1966). Elas atuam através dos

6. A política de crédito atua sobre instituições e segmentos específicos do mercado financeiro (interbancário e não bancário), induzindo a mudança na composição do balanço do setor privado, de modo a afetar as condições de financiamento. As operações realizadas pelo BC, que impactam sobre as dívidas privadas e valores mobiliários, alteram o seu balanço e se processa de várias formas, como alterações de colaterais e prazos de maturidade, contraparte em operações monetárias, empréstimos e aquisições de títulos privados. O objetivo principal destas medidas é reduzir as tensões do mercado interbancário, em particular os prazos e spread, bem como melhoria das condições de crédito ao setor não bancário. Ressalta-se que tal política pode gerar efeitos indiretos, na medida em que o mercado em que atua desempenha um papel importante na intermediação financeira. Destaca-se ainda que estas medidas são realizadas diretamente com os intermediários financeiros, o que sugere indiretamente melhorias gerais no mercado, em virtude do papel desempenhado por estas instituições. Porém em mercados específicos, o BC realiza operações de intermediação direta, sem a participação das instituições depositárias, interpondo-se entre investidores e prestatários.

7. As políticas de gestão de quase débito (quasi-debt mangement policy) - compra de títulos do governo e de agências governamentais, bem como a troca de títulos de longo prazo por curto prazo representam uma intermediação do BC entre o governo e o setor privado. Estas medidas buscam reduzir o prêmio de risco em relação a prazo e liquidez, dos títulos públicos em poder do mercado, promovendo a estabilidade do produto. A sua operacionalização ocorre por meio de compra de títulos públicos, inclusive títulos de agência, pelo BC, podendo ser financiado por meio de variação da base monetária, ou com recursos das reservas bancárias. Ressalta-se que estes ativos são uma importante referência para o mercado, na medida em corresponde a uma taxa de benchmark (livre de risco) e deste modo, afeta os custos de financiamento e o preço dos ativos em geral. A efetividade desta política de balanço exige, normalmente, um grande volume de compras para que se tenha um efeito sobre o rendimento destes títulos. 
canais de portfólio (q de Tobin e efeito riqueza) e do "habitat preferido"8, visando a redução da taxa de juros de longo prazo.

Por sua vez, a política de sinalização, se dá por um esforço de aprofundamento da comunicação com o público por parte da autoridade monetária. Assim, o Fed passou a sinalizar de forma mais clara e explícita as suas intenções futuras em relação ao comportamento da taxa de juros e quanto a compra de ativos financeiros (ou eventualmente qualquer outra decisão de PM). ${ }^{9}$ Sua eficácia depende da reputação do Fed e/ou da credibilidade da PM.

Quadro 1 - Mecanismos de Transmissão das Políticas Monetárias Não-convencionais.

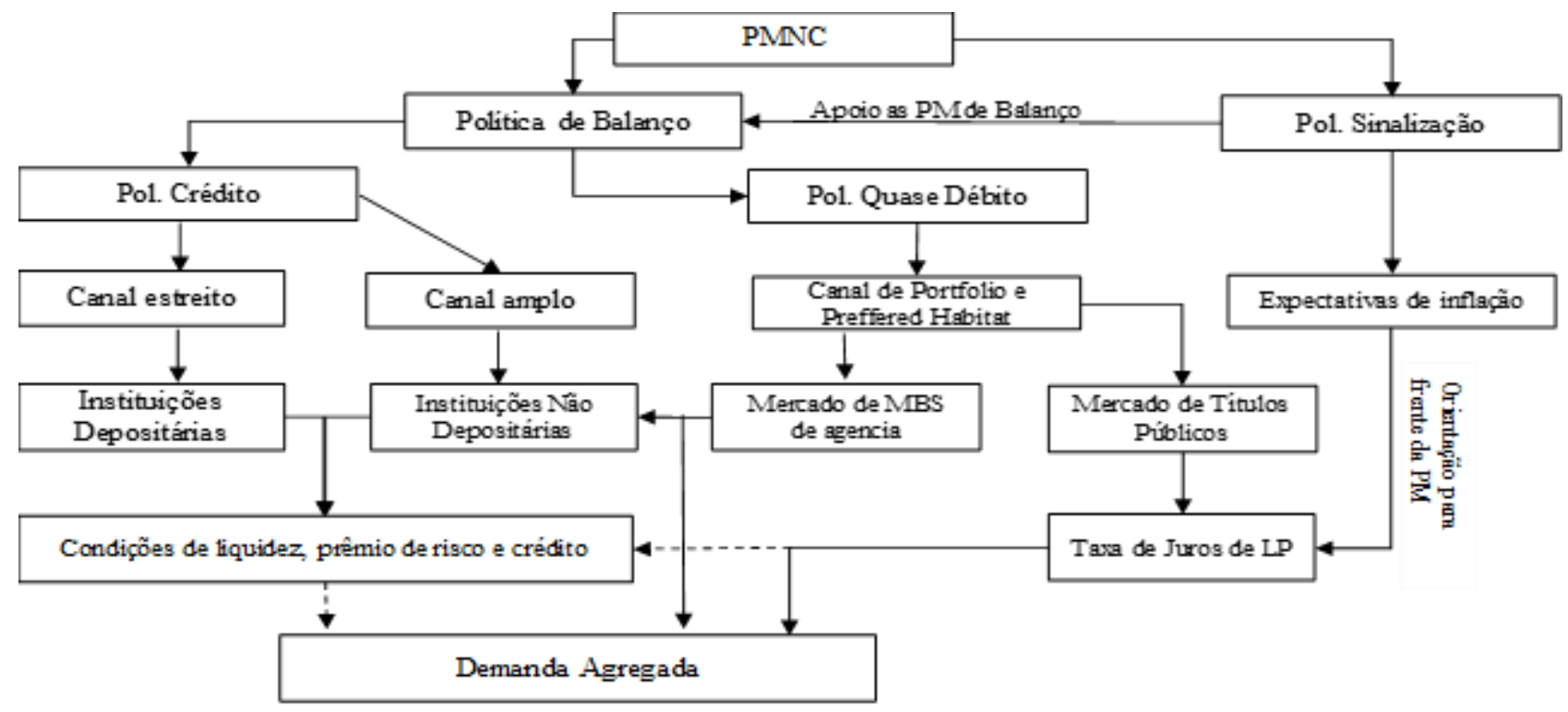

Fonte: Elaboração Própria

Finalmente, destaca-se que a revisão do novo consenso passou a aceitar a utilização de PMNC como instrumentos úteis para os períodos de exceção, tais como de ruptura financeira, como ocorrido nos anos de 2007 a 2014 nos EUA. Contudo, defendem que em períodos de normalidade, as políticas convencionais são mais do que adequadas para a condução da política monetária (PAULA, L. F. et al 2018).

\section{A VISÃO KEYNESIANA ACERCA DA INFLAÇÃO}

A identificação da teoria keynesiana em relação ao fenômeno inflacionário deriva da observação da ocorrência de fatores relacionados ao lado da demanda e principalmente da

8. A chamada teoria do habitat preferido (preffered habitat), supõe a existência de investidores com preferências heterogêneas e que, portanto, se especializam em diferentes classes de ativos. Assim, não se prevê a existência de uma relação estável (ou de uma curva de rendimentos) entre as taxas de juros de curto e de longo prazo - face a inexistência de uma arbitragem perfeita entre as diferentes classes de ativo.

9. Cabe destacar que, desde a popularização do regime metas de inflação (a partir dos anos 1990), verificou-se um esforço de aprimoramento dos canais de comunicação entre o banco central e o público. O que distingue a política de sinalização (em relação ao gerenciamento de expectativas) é a assunção de uma espécie de pré-comprometimento explícito por parte do Fed em relação à trajetória futura dos instrumentos de PM. 
oferta, como discutido em ARESTIS e SAWYER (2004a, 2004b, 2005, 2006 e 2008), DAVIDSON (2004 e 2006), MODENESI (2005), MODENESI et al. (2012), PALLEY (2013), dentre outros. O ponto de partida para esta discussão foi apresentado pelos autores, sendo proposto inicialmente por KEYNES (1971) que questionou a Teoria Quantitativa da Moeda e deste modo a sua principal implicação de uma relação positiva entre o estoque de moedas e o nível de preços de uma economia como o mecanismo central da geração de inflação. A proposição neoclássica de uma economia de troca pressupõe que a produção e venda ocorrem instantaneamente, e como não existe vazamento de renda, pois o investimento ex post equivale à poupança ex ante, as variações nos níveis de preços, normalmente, serão resultado de variações positivas do estoque de moeda.

Em contraponto, Keynes identifica dois tipos de inflação: a inflação de commodities (ou estoque) e a de renda. No primeiro caso, os preços de bens e serviços nos mercados à vista (spot) dependem dos contratos estabelecidos no passado, que determinaram a oferta para o período presente. Como a produção demora um tempo de calendário para ser realizada, uma variação da demanda ou oferta corrente, não esperada, promoverá excesso ou escassez de mercadorias, impactando sobre o nível de preços da economia e consequentemente sobre os ganhos dos detentores de estoques. O segundo é decorrente do anterior, na medida em que os contratos futuros (preços a prazo) serão influenciados pelos preços à vista. Neste caso, quando os preços sobem acima da produtividade marginal do capital, geram ganhos de renda para os proprietários dos fatores de produção (DAVIDSON, 2006).

A implicação de uma definição mais precisa das causas da inflação, segundo DAVIDSON (2006), evidencia que o aumento de preços spot (inflação de estoque) apresenta uma tendência de se dissipar, embora possa demorar algum tempo. Na medida em que o aumento dos preços (a vista) tende a estimular a produção industrial e consequentemente o aumento de estoques reduzirá os preços, pois não induz aumento dos custos de produção. No entanto, o risco é de que o aumento dos preços spot influencie a alta dos contratos relacionados aos preços a prazo (inflação de renda), promovendo uma elevação contínua dos preços. Para debelar este tipo de inflação o mecanismo mais eficiente seria uma política de renda que evitasse um aumento da renda monetária acima da produtividade por fator produzido. Segundo Weintraub, apud DAVIDSON (2006:698), existem três causas para a inflação de renda:

1. Diminishing returns inflation where the marginal productivity of workers decreases as output flow increases, even as the money cost per unit of factor input is unchanged. Diminishing returns inflation is probably small in most industrialized nations. Nevertheless, it is a real cost of expansion toward full employment where no one should have a vested interest in obtaining low prices just because output is low and employment is low. 2. Monopoly or profits inflation occurs when entrepreneurs attempted to raise prices relative to production costs, thereby increasing profit margin per unit of output. 3. Factor price inflation occurs when owners of the factor inputs of production demand higher monetary income for each unit of input relative to any improvement in productivity per unit of input, such as wage-cost inflation.

Segundo DAVIDSON (2006) e PALLEY (2013) uma boa exemplificação para este tipo de inflação pode ser observada nos EUA desde a década de noventa. Para os autores, até a década de 80 , o processo inflacionário não promoveu uma disputa pela distribuição da renda entre trabalhadores e empresários, pois o governo, como observado nos EUA, estava disposto a criar demanda efetiva suficiente, por meio de acomodação monetária, que 
permitisse uma evolução conjunta dos preços e da produtividade marginal do trabalho e mantivesse a economia próxima ao nível de pleno emprego. Tal cenário mudou a partir da década de 90 como consequência do processo de liberalização e globalização, na qual a ligação entre os preços dos bens e serviços e a produtividade marginal do trabalho foi interrompida. A estagnação e perda real dos salários de uma parcela significativa de trabalhadores, associada ao aumento das desigualdades de renda nos países desenvolvidos, promoveu uma queda na renda e na demanda destas economias. Este hiato de demanda foi ocupado pelo sistema financeiro, favorecido pelo processo de desregulamentação financeira dos anos 80 e pela sua capacidade de inovação, promovendo uma ampliação do volume de empréstimos para aquisição de bens duráveis, particularmente de imóveis residenciais, resultando no aumento do nível de endividamento das famílias e na formação de bolhas nos preços de ativos.

De acordo com DAVIDSON (2006:700), as causas da inflação segundo Weintraub são sintetizadas pela seguinte relação:

$$
P=k\left(\frac{w}{A}\right)
$$

A partir desta relação, tem-se que o nível de preços $(P)$, depende da margem de lucro $(k)$ e da relação entre o salário médio do trabalho $(w)$ e a produção física média do trabalho (A). Como decorrência, a inflação de renda deve ser combatida por meio de política que limite os lucros monetários e salários acima da produtividade do trabalho. Nesta perspectiva de inflação de renda, DAVIDSON (2004 e 2006) argumenta que uma estratégia de combate a elevação de preços mais eficiente pode ser implementada por meio de uma política fiscal sobre a renda (tax-based incomes policy).

Este mecanismo de política fiscal anti-inflacionária foi apresentado por Weintraub que propõe a utilização de impostos punitivos sobre a renda de grandes empresas que acomodam aumentos nas suas margens de lucratividade ou dos salários acima dos ganhos de produtividade. Tal imposto se justifica, na medida em que a elevação do preço de bens e serviços destas empresas impacta sobre os preços absolutos de uma economia e deste modo devem ser restringidos, na medida em que são prejudiciais a sociedade (DAVIDSON 2004, 2006 e SICSU, 2003).

A introdução da política fiscal punitiva sobre a renda excessiva deveria ser permanente, evitando a sua impotência no caso de uma medida temporária, além de implantada como um sistema de sanções, ao invés de recompensa. Segundo DAVIDSON (2006:702): "Weintraub suggested that TIP was similar to the way the government enforces speed limits on the nation's highways. If one exceeds the speed limit - which is always in place - one pays a speeding fine. Governments never pay good drivers for not exceeding the speed limit"

Para SICSU (2003:129), esta política fiscal é mais eficaz do que a política monetária convencional de taxa de juros. Nesta última, observa-se que embora possa haver efetividade na queda da inflação, o efeito sobre atividade econômica é uma elevação da taxa de desemprego e baixa taxa de investimento. Tal fato decorre do impacto recessivo da elevação da taxa de juros sobre a demanda e os custos financeiros, ao afetar todas as empresas e trabalhadores, independente do setor e do nível de pressão que cada um destes exerce sobre a inflação. Nesta mesma linha de argumentação DAVIDSON (2006:702) afirma que:

Unfortunately, the United States and many other nations have never seriously attempted to develop a permanent penalty-oriented TIP. Instead, inflation has been fought via the typical monetarist "incomes policy of fear"-that is, restricting the 
growth of the money supply so as to create slack markets via recession. Those who raise their wages above productivity growth will then find themselves priced out of the marketplace. The real cost of such a monetarist incomes policy to many industrialized nations in the recent past has been significant. For countries such as Germany and France, double-digit unemployment rates-previously unseen since the Great Depression-have become the norm.

Uma última abordagem sobre fontes de inflação é apresentada por ARESTIS e SAWYER (2005), a partir da discussão sobre o tamanho da capacidade instalada de uma economia que não corresponde, necessariamente, ao nível de pleno emprego da força de trabalho. Nesta perspectiva, as pressões inflacionárias decorrem do nível de operação das empresas, do conflito distributivo e das pressões de demanda. No primeiro caso, as empresas operam abaixo ou acima da sua capacidade normal, determinando diversos níveis de desemprego, de renda e da demanda e consequentemente impactando sobre os níveis de preços da economia. O conflito distributivo deriva da tentativa de apropriação da renda por parte dos trabalhadores e empresários:

\begin{abstract}
"An increase in the rate of inflation can be viewed as arising from some combination of the intention of some groups to increase their share of income and on enhanced opportunity to do so. A higher level of demand for labour may, for example, be seen as an enhanced opportunity for workers to increase their share. But a related higher level of demand for output would allow firms to increase their profits" (ARESTIS e SAWYER, 2005, p.960).
\end{abstract}

\title{
4. POLÍTICA MONETÁRIA KEYNESIANA
}

A PM keynesiana exibe um conjunto de elementos históricos e teóricos que a torna substancialmente diferente da visão convencional do NCM. O ponto de partida da discussão acerca de uma economia monetária da produção assume as funções primordiais de um BC, relacionadas ao apoio às finanças do estado, à promoção do crédito e a estabilidade do sistema bancário, bem como identifica a importância do processo de evolução da firma bancária e o papel desempenhado por estas instituições. Um segundo aspecto aborda as causas e as políticas adequadas para lidar com processos inflacionários. Num terceiro ponto, destaca-se a importância da coordenação entre políticas econômicas, como um importante elemento para a eficiência da PM. A quarta característica, relaciona-se diretamente a PM, no que se refere aos objetivos do $\mathrm{BC}$, bem como à importância da sinalização para o público e os instrumentos clássicos.

\subsection{Funções do BC}

Inicialmente, tem-se que as três funções históricas atribuídas ao $\mathrm{BC}$ referem-se às de um banco que possa suprir a necessidade de financiamento do estado, em períodos de exceção, minimizando o risco de um default da dívida pública. Em outro momento, buscou a promoção de crédito, via estimulo aos bancos comerciais, concomitante com baixas taxas de juros, limitadasà situação em que uma economia não estivesse no nível de pleno emprego, em virtude dos problemas inflacionários, além da garantia da liquidez do sistema bancário e consequentemente à confiança do público nas instituições depositárias e na moeda escritural, promovendo a estabilidade das instituições financeiras, enquanto emprestador de última instancia (DAVIDSON, 2006 e CARVALHO, 1995). 
De modo complementar, identifica-se o processo de desenvolvimento do sistema bancário, descrito por CHICK (1994), no qual este evoluiu de pequenas instituições depositárias, principalmente de poupança, com baixos volumes de captação e empréstimos, na qual a poupança era uma condição necessária para o investimento, para os modernos bancos, desde a década de 70 . Estas instituições depositárias passam a administrar ativamente os dois lados do balanço, em um ambiente de ampliação da concorrência, tanto entre os próprios bancos, quanto em relação às demais instituições financeiras. A mudança de foco em relação às reservas (liquidez) é substituída pela adequação da disponibilidade de capital, como resultado do fim das exigências de reservas, e os depósitos tornam-se amplamente aceitos como meio de pagamentos (CHICK, 1994).

Ao longo dos diversos estágios de evolução do sistema bancário, a relação entre a poupança e investimento se inverte, tornando-se uma fonte perturbadora a estabilidade da economia, na medida em que os bancos passam a "emprestar um valor que é um múltiplo das reservas" (CHICK, 1994:12). Como resultado, "o investimento podia preceder a poupança: a poupança equivalente, em primeira instância, seria constituída pelos novos depósitos bancários oriundos da expansão dos empréstimos" (CHICK, 1994:17). Neste contexto, a elevada capacidade dos bancos de criarem crédito, independente das políticas econômicas, torna-se um importante elemento de explicação para a persistência dos processos inflacionários.

\subsection{Inflação}

Uma segunda questão refere-se às causas da inflação, a partir da definição de KEYNES (1971), expressas pela inflação de estoque e inflação de renda, têm fortes implicações para a definição da política econômica adequada para tratá-la. No caso de inflação de estoque (spot) políticas que desestimulem a demanda agregada, como políticas de taxa de juros, poderão ter algum efeito sobre o nível de preços reduzindo a diferença entre a demanda e a oferta por bens e serviço (PALLEY, 2009). No entanto a taxa de juros pode ter efeitos adversos sobre o nível de investimento, termos de troca, fluxo de capitais e câmbio, impactando negativamente sobre o nível de atividade econômica, bem como sobre a estabilidade financeira (SICSU, 2003 e ARESTIS, 2009).

No entanto, quando as causas da inflação são provenientes de conflito distributivo, como a elevação nos custos de produção e aumento dos lucros acima da produtividade do trabalho, estas políticas de demanda são inócuas e consequentemente a PM não tem grande efetividade. Neste caso, são necessárias políticas de renda "that is, some policy that constrains the owners of factors of production from demanding increases in the money income that exceed productivity increase per factor unit (DAVIDSON, 2006:698). Ademais, como enfatizado por ARESTIS (2009), a inflação poderá ser gerada por outros fatores, como custos e pelo tamanho da capacidade instalada da economia, sendo que nestes casos, assim como na situação de inflação de renda, a taxa de juros e consequentemente a PM não tem grande efetividade.

\subsection{Coordenação das Políticas Econômicas}

Uma terceira característica refere-se à necessidade de coordenação da política econômica e parte do princípio de que uma economia de mercado não apresenta uma "mão invisível" que conduza a economia para a situação de "ótimo de Pareto", exibindo deficiências que em boa medida podem ser suplantadas pelo desenvolvimento de 
instituições que reduzam os riscos e incertezas de mercado (CARVALHO, 2009). Neste contexto, o planejamento econômico, executado pela coordenação entre as políticas econômicas, desempenha um papel fundamental, dado que estas interagem entre si, os resultados esperados dependem do estado das demais políticas, bem como do próprio ambiente econômico (SICSU, 1998).

Para atingir os objetivos pretendidos, a política econômica utiliza-se de um instrumento para cada objetivo de modo a não ser restringida pelo princípio de Tinbergen, no qual é enunciado que a existência de mais de um objetivo para um mesmo instrumento, promovera a ineficiência das políticas econômicas, no caso da existência de trade off entre os objetivos. Ademais os diversos instrumentos utilizados pelas políticas econômicas apresentam mecanismos de transmissão específicos, bem como a sua intensidade e defasagem, podendo gerar resultados bem diferentes dos almejados. Por outro lado, a característica comum destes refere-se ao objetivo de alterar a demanda agregada (SICSU, 1998).

Desta forma, para que um instrumento de PM tenha maior efetividade, é necessária a coordenação com os demais instrumentos de políticas, particularmente com a política fiscal. Conforme destacado por SICSU (1998:94):

Embora a coordenação da utilização dos instrumentos de política macroeconômica seja imprescindível para a realização de uma política monetária bem-sucedida, outros dois critérios devem ser observados para o julgamento sobre a eficiência de uma determinada ação monetária. Uma política monetária eficiente seria aquela que, além de criar o mínimo de utilização-contraditória entre seus instrumentos e os instrumentos de política fiscal, persegue um objetivo não-ambíguo e, também, emite o máximo de sinais aos agentes a fim de estimulá-los a agir no mesmo sentido da direção apontada/adotada pelas autoridades.

\subsection{Incentivos a atividade econômica}

Um quarto aspecto da discussão enfatiza os objetivos da PM, relacionados ao estímulo ao crédito de curto prazo, para as antecipações de despesas e o investimento empresarial que promove aumento da demanda agregada no curto prazo e expansão da capacidade instalada das firmas no longo prazo. Para tanto, deve-se destacar que a moeda, enquanto reserva de valor, exibe características similares a de qualquer outro ativo da economia, pois permite aos indivíduos acumular e transportar riqueza ao longo do tempo, sendo a sua particularidade a inexistência de remuneração que é compensada pelo prêmio de liquidez.

Esta propriedade, associada à existência de incerteza fundamental, torna este ativo uma alternativa dos agentes, para lidar com alterações de expectativas em relação ao futuro, exibindo a racionalidade do comportamento de preferência pela liquidez. Como resultado, a simples existência de moeda afeta as decisões dos agentes econômicos e qualquer política econômica que altere o estoque de moeda e/ou os preços de ativos, induzirá as alterações de portfólio dos agentes, que dependendo das decisões destes terão impacto sobre variáveis reais da economia (SICSU, 1997).

Nos termos definidos por Keynes (1971), a renda monetária gerada em uma economia pode ser utilizada para a compra de bens e serviços, inclusive bens de capital (circuito industrial) ou retida sobre a forma de ativos não-reprodutíveis e moeda (circulação financeira). A inter-relação entre estes dois circuitos intermediada pela taxa de juros é exatamente o ambiente onde a PM, por meio de seus instrumentos, impacta sobre a 
liquidez de uma economia. Um BC terá efetividade em sua PM, estimulando que os agentes econômicos transfiram recursos da circulação financeira para a circulação industrial, ou viceversa, variando o nível de gastos, e deslocando a demanda agregada o produto, o emprego e o nível de renda da economia.

Nesta perspectiva, normalmente a PM promove uma combinação de efeitos nas variações das quantidades (reservas) e dos preços (taxa de juros), embora o resultado dependa da preferência pela liquidez dos agentes, em destaque a preferência dos bancos e de sua capacidade de reorganizar a sua carteira, eliminando os efeitos de quantidade e consequentemente o impacto sobre o nível e preços. Deste modo o objetivo pretendido pelo $\mathrm{BC}$ dependerá da preferência pela liquidez dos indivíduos, do estado de expectativas do mercado e do grau de confiança, bem como do arranjo institucional de cada país, meios pelos quais a taxa de juros é transmitida (CHICK e DOW, 2002).

É nestes termos que a teoria monetária pós-keynesiana define o papel da PM, na qual a intervenção do $\mathrm{BC}$ sobre a liquidez da economia, altera os preços relativos dos diversos ativos existentes, incluindo o próprio prêmio de liquidez da moeda, induzindo os agentes econômicos a revisarem a sua composição de portfólio, alterando o trade off entre prêmio de liquidez e rentabilidade, no sentido almejado pelos objetivos da PM. Segundo SICSU (1997:92):

Uma política monetária que visa à redução do desemprego deve estimular o animal spirits da economia de tal forma que a incerteza futura tenha uma influência mais restrita sobre as decisões de investimento: busca-se aumentar o retorno total esperado relativo dos ativos de capital. Dessa forma, uma alteração de composição de portfólio do público a favor da aquisição de máquinas e realização de obras tornar-se-ia menos arriscada. A troca da liquidez da moeda com rendimento nulo pela iliquidez dos ativos de capital com retornos esperados positivos deve se transformar, pela ação da política monetária, na opção mais rentável e segura para os agentes, consequentemente, reduzindo o desemprego.

A eficiência da PM, por um lado, prescinde da emissão de sinais (informação) ao mercado acerca das intenções do $\mathrm{BC}$, de modo a estimular que os agentes atuem na mesma direção. A sinalização desempenha um papel importante, permitindo não só uma amplificação dos instrumentos operacionais (operações de mercado aberto, redesconto e reservas compulsórias), mas também reduzindo a incerteza dos agentes nas decisões de gastos, em especial, no investimento empresarial. Em grande medida, o efeito da comunicação sobre eficiência da PM, deve-se ao fato de que os indivíduos reconhecem que governo dispõe de instrumentos potentes que lhe permite alcançar os objetivos anunciados, alterando o ambiente econômico. Segundo SICSU (1988:96):

(...) os sinais emitidos pelas autoridades podem induzir à formação de expectativas auto-realizáveis: agentes acreditam que determinado contexto futuro ocorrerá, então, tomam decisões consistentes com suas expectativas, que terminam por ser validadas pela realidade - dado que os agentes agiram para construir aquele cenário esperado.

Neste ponto destaca-se a proposição de KEYNES (1982:166-167) de que "empregamos a nossa inteligência em antecipar o que a opinião geral espera que seja a opinião geral (...) A sabedoria universal indica ser melhor para a reputação fracassar junto com o mercado do que vencer contra ele". Deste modo, em períodos normais, as sinalizações de PM que sejam capazes de influenciar a opinião dos indivíduos em relação ao 
comportamento médio dos agentes, no futuro, terão mais efetividade, reduzindo as incertezas e estimulando atitudes no sentido almejado pela política econômica.

Ademais, como enfatizado por BIBOW (2005), o conceito de convenção é relevante para a discussão sobre o canal de expectativas e a eficácia da PM. Embora possam ser estabelecidos certos padrões por parte dos agentes em relação à taxa de juros, as alterações desta, por meio de PM, impactam sobre as expectativas dos agentes de modo que estes irão caminhar no sentido indicado pela autoridade monetária. No entanto, em determinadas circunstâncias, o canal de expectativas pode operar em sentido oposto a sinalização da autoridade monetária, de modo a neutralizar os seus efeitos. Segundo BIBOW (2005:20): "More generally, then, one may consider policy communication as the key tool directed at steering market expectations in line with policy intentions; backed up by the possibility of actually carrying out open market operations if that threat is held credible by the markets". De forma complementar, BIBOW (2006:21), argumenta que:

due to the insight that the long-period norm is established by someconvention Keynes became far more alert to the complexity of influence of monetary policies on interest rates. In theory, the problem is that the convention the financial system comes up with may be wrong and the economy gets stuck in an unemployment equilibrium as a consequence. In practice, the convention is moulded largely by monetary policy itself anyway, but the authority may fail to change it when needed namely for failure of convincing the banks to follow suit.

De modo complementar, a operacionalidade depende dos instrumentos clássicos de PM, quais sejam redesconto, reservas compulsórias e operações de mercado aberto. No primeiro caso, a teoria pós-keynesiana idêntica à função de provisão de liquidez, como essencial para atuação do $\mathrm{BC}$ enquanto emprestador de última instancia. Embora seja operacionalizada, em períodos normais, por meio de taxas punitivas sobre empréstimos de liquidez e acesso excepcional a uma fração das reservas depositadas, a adoção deste instrumento pode representar limitações à utilização dos outros dois, na medida em que afeta a base monetária e a taxa de juros, reduzindo a eficácia da PM.

As reservas compulsórias, por outro lado, representam a possibilidade de a PM afetar as decisões de curto prazo dos agentes econômicos, particularmente promove uma variação na quantidade de moeda manual nos bancos depositários e nas taxas de juros, alterando o volume de empréstimos (SICSU, 1998:100). Na medida em que este instrumento não afeta diretamente o mercado interfinanceiro, mas os custos dos depósitos (spread), principalmente quando BCs adotam critérios de reservas médias, a sua potência para influir sobre os investimentos é questionada. Ressalta-se ainda, que as exigências de reservas compulsórias se constituem em um instrumento prudencial, na medida em que obriga os bancos a recolherem uma parcela dos depósitos à vista e a prazo, limitando os riscos de iliquidez.

As operações de mercado aberto são identificadas como o principal instrumento da PM, pois estas alterarem a taxa básica de juros de curto prazo, afetando a taxa de lucro das instituições bancárias (BIBOW, 2005). Esta taxa, adicionada de um markupdetermina a taxa de desconto utilizada pelos empresários no cálculo da eficiência marginal do capital. Embora seja um instrumento de efeito indireto, pois alterações na taxa de juros via sistema interbancário, influenciam e não determinam a mudança de portfólio dos agentes, esta PM objetiva, ao ampliar a liquidez do sistema bancário, estimular uma troca de ativos mais líquidos por ativos menos líquidos representados por bens de capital. 


\title{
5. MECANISMOS DE TRANSMISSÃO DA POLÍTICA MONETÁRIA
}

A teoria monetária Pós-Keynesiana identifica a capacidade do BC em manipular o estoque de moeda (reservas bancárias), para alterar a quantidade e a taxa de juros dos ativos líquidos (nos mercados monetários). Deste modo o BC detém a capacidade de definir e poderá impor a taxa básica de juros de uma economia. No entanto, não existe obrigatoriamente, uma relação direta e de mesma magnitude com as demais taxas de juros da economia, inclusive em relação às taxas de longo prazo. Conforme abordado por ARESTIS e SAWYER (2006:853) "[i]t is not changes in the absolute level of the rate of interest, but changes in relative interest rates that provide the mechanism whereby the preferences of borrowers are reconciled with the desire to hold the resulting deposits".

Deste modo, as alterações na taxa de política irão induzir e não determinar a reestruturação do portfólio dos agentes privados, de modo a aumentar ou reduzir a demanda por ativos financeiros e reproduzíveis, estimulando ou deprimindo a produção a renda e o consumo da economia no curto e longo prazo. Nesta perspectiva, a PM opera na esfera da circulação financeira, estimulando a transferência de recursos para a circulação industrial, notadamente em variações nos empréstimos de curto prazo (capital de giro), através de efeitos de quantidade e preço, e na taxa de investimento, por meio dos efeitos da taxa básica sobre o preço dos demais ativos (CARVALHO, 1994:46). Ademais os impactos das mudanças na taxa de juros dependerão da capacidade do BC alterar as expectativas de mercado (BIBOW, 2005).

Como consequência, as decisões de portfólio dos agentes privados (bancos e firmas) irão depender de um conjunto de elementos relacionados às suas expectativas e incertezas sobre o comportamento futuro da economia, além do grau de confiança no prognóstico, que determinam a preferência pela liquidez. Ademais os agentes irão estabelecer comparações entre os preços correntes dos ativos em relação ao que entendem por preços normais, e segundo CARVALHO (1994:46):

\begin{abstract}
É a arbitragem entre valores correntes e normais de um mesmo título ou entre preços relativos e normais dos diversos tipos de títulos que transmite os impulsos introduzidos pela autoridade monetária através das operações de mercado aberto às ações dos operadores finais, demandantes de bens e serviços da economia.
\end{abstract}

De forma mais específica, uma PM que objetive reduzir o desemprego irá depender das ações do BC, e por outro das reações dos bancos comerciais, das firmas e dos consumidores. Em última instancia, dependerá das decisões de portfólio de cada um dos agentes (SICSU, 1998:104). A principal implicação do dinheiro endógeno refere-se à existência de uma forte interação entre a PM e a preferência pela liquidez cujos resultados para a atividade econômica (investimento) irão influenciar o comportamento futuro de variáveis macroeconômicas que são utilizadas pelo $\mathrm{BC}$, na determinação das taxas de juros. Segundo ARESTIS e SAWER (2006:853), "[t]he Central Bank changes the key interest rate from time to time, which leads to the question of the forces that influence or determine the Central Bank interest rate in the longer term"

Conforme abordado na seção anterior, as políticas de open marketafetam as taxas de juros de curto prazo e o custo das reservas e, dependendo da preferência pela liquidez dos agentes e da arbitragem na curva de rendimentos ${ }^{10}$, serão transmitidas para as taxas mais longas, impactando sobre o portfólio dos agentes, a demanda e principalmente o

\footnotetext{
${ }^{10}$ Segundo BIBOW (2005:15) "But Keynes stressed that short-term and longer-term rates were related and that the term structure of interest rates was largely driven by bank behavior.
} 
investimento. Por outro lado, as variações nas reservas compulsórias, dada a preferência pela liquidez dos agentes, terão efeito sobre o volume de moeda disponível nos bancos, afetam os custos e o volume de empréstimos de curto prazo. Deste modo, a PM para ter efeito sobre a atividade econômica irá depender do comportamento dos agentes, bancos, firmas e consumidores. A seguir são apresentados os "três" estágios de transmissão da PM.

Os bancos representam o primeiro estágio da transmissão da $\mathrm{PM}$, pois estes estabelecem uma relação direta com o BC, por meio de operações de mercado aberto (interbancário), reservas compulsórias e redesconto. Ao promover a compra ou venda de ativos líquidos (no interbancário) e/ou exigências de reservas, o BC altera a quantidade de moeda disponível e o preço/custo dos bancos comerciais, almejando que estes caminhem na direção sinalizada pela PM (CARVALHO, 1994:48). No entanto, os bancos são agentes que tomam decisões, em um ambiente de incerteza, e dadas a sua principal característica de gerenciar a maturidade dos seus ativos e passivos, estes exibem expectativas de retorno e preferência pela liquidez. (PAULA, 1999).

Desta forma, as alterações nos volumes de reservas e nos preços, por meio de mudanças nas reservas bancárias, serão transmitidas aos empréstimos e financiamentos bancários. Segundo ARESTIS e SAWYER (2006), a taxa de empréstimos dos bancos é estabelecida a partir de um markupsobre a taxa básica, sendo que o markupvaria de acordo com a preferência pela liquidez, poder de mercado e nível de aversão ao risco, além da qualidade de crédito concedido em relação ao perfil dos mutuários. Ressalta-se ainda que a preferência pela liquidez se altera em decorrência da incerteza gerada por mudanças no ambiente de negócios e/ou expectativas ao longo de um ciclo de negócios.

A preferência pela liquidez na perspectiva dos bancos pode ser entendida como as decisões de portfólio, em relação ao lado do ativo. Normalmente os principais elementos de sua carteira são os empréstimos, que são ilíquidos e os títulos que variam de alta até baixa liquidez. Logo, as mudanças na preferência pela liquidez farão com que este altere a composição de seu ativo, e ao fazê-lo, impacta sobre a demanda e oferta de títulos no mercado secundário, alterando desta forma o preço dos diversos títulos, além da concessão de empréstimos adicionais. Deste modo, as mudanças na preferência pela liquidez, que alteram a composição do portfólio dos bancos, afetam os preços relativos e consequentemente a operacionalização da PM e seus efeitos sobre a demanda agregada (ARESTIS e SAWYER, 2006).

Uma PM de compra de ativos líquidos (p. ex. títulos do governo) que promova um aumento da quantidade de reservas nos bancos comerciais terá três possíveis resultados: i) Retenção do excesso de moeda (aumento de reservas voluntárias); ii) Compra de ativos financeiros nos mercados secundários; e iii) Compra de ativos financeiros nos mercados primários. Na primeira situação descrita, os bancos operam de forma a esterilizar o excedente de moeda na economia impedindo que a PM tenha qualquer efeito. Segundo CARVALHO (1994:48): "Em circunstâncias de acentuada insegurança e na ausência de alternativas, os bancos podem preferir o prêmio de liquidez da moeda à possibilidade de ganhos pecuniários com aplicações".

Por outro lado, a compra de ativos, pelos bancos, em mercados secundários, transporta a PM inteiramente para a circulação financeira. Nesta situação, três resultados poderão emergir: i) ocorrerá uma realocação entre ativos financeiros nos portfólios dos detentores de títulos, sem efeito significativo sobre os ativos de capital; ii) deslocamento de uma parte dos recursos aplicados em títulos para os ativos de capital, aumentando a demanda por crédito e investimento; e iii) As instituições depositárias poderão repassar o 
excedente de moeda para outras instituições financeiras não bancárias, de modo que o efeito dessa política dependerá da forma de utilização destas. (CARVALHO, 1994:49).

Na terceira possibilidade, a compra de títulos de instituições não financeiras no mercado primário pelos bancos comerciais, tende a apoiar a necessidade de capital de giro e investimento empresarial das firmas que promoverão a expansão da demanda agregada. Neste ponto, ressalta-se a visão keynesiana na qual a função histórica dos bancos é apoiar a necessidade das firmas, por recursos monetários de curto prazo. Estas produzem a partir das expectativas em relação à demanda por seus bens e serviços, e desta forma, recorrem aos bancos para adiantamentos ${ }^{11}$, normalmente necessários, para 0 pagamento a fornecedores e empregados que antecedem a venda ao mercado. Ademais, tais recursos são necessários para a realização de investimentos, na medida em que apoiam financee o funding.

Deve destacar que a partir da preferência pela liquidez das instituições depositárias identifica-se a possibilidade de racionamento de crédito, como um comportamento "normal" dos bancos, como observado por DOW (1996) em relação às pequenas empresas ${ }^{12}$. Ademais, o nível de racionamento de credito tende a se alterar ao longo do ciclo econômico, como decorrência da variação na percepção dos bancos em relação aos riscos de inadimplência, ampliando a exigências de colaterais e evitando compromissos adicionais que comprometam a sua liquidez (DOW, 1996). Tal questão também é abordada por WOLFON (1996), que argumenta que o nível de racionamento de crédito irá depender da fase do ciclo econômico.

O segundo estágio de transmissão da PM irá depender das decisões empresárias de produção e investimento, caso os bancos caminhem na direção sinalizada pela PM, sendo as preferências pela liquidez e as mudanças nas taxas relativas de empréstimos, ajustadas por markup, a referência para o custo de capital das firmas, e não na taxa básica de juros (ARESTIS e SAWYER, 2006). Deste modo uma vez que existam instituições financeiras dispostas a fornecer financiamento às empresas, a um determinado preço, estas irão confrontar o custo de capital ( $r$ ) a eficiência marginal do capital $(E M g C)$, além das suas próprias expectativas de curto e longo prazo e preferência pela liquidez, para decidirem sobre novos investimentos.

A decisão de investimento, condicionada à igualdade entre $\mathrm{EMgC}$ e a taxa de juros, equivale a proposição de que o preço de oferta é igual ao preço de demanda ${ }^{13}$, sendo pouco influente sobre as decisões de curto prazo, na medida em que as expectativas para períodos mais curtos, tendem a aceitar a manutenção das condições econômicas atuais no ambiente de negócios. Nos termos definidos por KEYNES (1982) é suposto que a taxa de juros tem pouco impacto sobre as decisões de investimento de curto termo, bem como em relação ao work capitale o liquid capital, sendo estes dois últimos influenciados pelo nível de renda e expectativas nas variações nos preços, respectivamente.

\footnotetext{
${ }^{11}$ Segundo DAVIDSON (2006:693) "Keynes recognized that positions in working capital are necessary because final goods take time to produce. Keynes's monetary theory of production explains why and how entrepreneurs attempt to meet their payroll (and other) contractual obligations."

${ }^{12}$ Essas dasses de empresas pequenas com baixas bases de recurso são particularmente vulneráveis ao comportamento da taxa de juros, uma vez que, geralmente, operam em mercados competitivos nos quais há pequena margem para estratégias defensivas, ocorre imperfeição do mercado de capitais e, normalmente, há informações imperfeitas relativas à falta de registro (DOW, 1996).

${ }^{13} \mathrm{~A}$ diferença entre estas duas abordagens referem-se ao fato de que $\mathrm{EMgC}=\mathrm{r}$, não oferece uma solução, quando as expectativas de fluxo de caixa são negativas, como normalmente ocorre nos primeiros períodos da realização de investimento, ao passo que a segunda alternativa $\mathrm{Ps}=\mathrm{Pd}$, sempre poderá ser determinada.
} 
De outro modo, a taxa de juros e as expectativas das firmas são relevantes para as decisões de investimento em capital fixo que envolve um prazo longo de maturação e retorno. Em relação à primeira, a taxa de desconto depende da taxa de remuneração livre de risco e do spreadde risco. Para que o investimento seja sensível às variações da taxa de juros, o spreadnão poderá ser muito elevado, caso contrário, a incerteza em relação à demanda poderá inibir a realização do investimento. Neste ponto deve-se ressaltar que a taxa de juros é relevante para a decisão marginal de investimento, na medida em que determina o tamanho do projeto a ser implantado.

No que se refere às expectativas, os rendimentos esperados e o estado de confiança regem as decisões de investimento de longo prazo. O primeiro refere-se ao fluxo de caixa esperado dos projetos de investimento. No entanto, KEYNES (1982) enfatiza o estado de confiança, a partir do conceito de incerteza não probabilística. Neste as decisões dos agentes são exógenas e referem-se ao grau de confiança que estes estabelecem a partir de suas próprias conjecturas sobre a projeção de rendimentos esperados. Deste modo, os agentes podem partir de uma mesma expectativa, mas tomarem decisões diferentes, como decorrência de divergências em termos do grau de confiança nas expectativas.

Como resultado do exposto, as implicações para a PM são substanciais, na medida em que alterações na taxa de juros e/ou no fornecimento de crédito terão pouco efeito sobre os investimentos de curto prazo, sendo mais significativos os efeitos das expectativas de curto prazo. Por outro lado, as taxas de juros são mais influentes nas decisões marginais de investimento de longo prazo, uma vez que as expectativas de rendimentos e principalmente o estado de confiança nestas expectativas serão determinantes para as decisões de investimentos em capital fixo. Segundo KEYNES (1982:171) "Da minha parte sou, presentemente, algo cético quanto ao êxito de uma política meramente monetária orientada no sentido de exercer influência sobre a taxa de juros". Nesta perspectiva, a principal contribuição de uma PM será a manutenção da taxa de juros baixa e estável de modo a proporcionar um ambiente favorável à realização de negócios.

Ressalta-se que esta proposição de KEYNES (1982) acerca da baixa efetividade da PM em alterar a taxa de juros e estimular o investimento empresarial destoa da proposição de CARVALHO (1994) e SICSU (1998, na medida em que estes autores identificam que a PM terá maior efetividade em alterar o estoque de reservas e a taxa de juros de curto prazo, além de maior impacto sobre as decisões de investimento empresarial. Nesta discussão, entretanto, observa-se que as divergências se referem ao grau de efetividade de uma PM, tanto em alterar a taxa de juros, como de induzir mudanças nas decisões de portfólio das firmas e deste modo estimular a transferência de recursos monetários da circulação financeira para a circulação industrial.

No terceiro estágio de transmissão da PM, representado pelas decisões de gastos de consumo, a partir de fontes de financiamento disponíveis (por exemplo, crédito bancário), embora não seja uma temática amplamente abordada por KEYNES (1971 e 1982), uma vez que este enfatizou o investimento como o elemento central da demanda, esta questão passou a ser relevante nas últimas décadas, como sublinhado por PALLEY (2009) a partir da década de 80. Segundo BIBOW (2005), Keynes já ressaltara que mudanças inesperadas no valor do capital das famílias, particularmente no mercado de ações, poderiam gerar impacto de curto período na preferência pela liquidez destes indivíduos e consequentemente na propensão marginal a consumir.

Tal situação poderia ser agravada, quando a fonte de recursos para aplicação fosse emprestada. Ademais, Keynes identificava que estes eram mais fortemente influenciados 
pelos ganhos e perdas nos títulos detidos, do que propriamente nos seus rendimentos. Segundo (BIBOW, 2005:24):

"With a stock-minded public as in the United States today, a rising stock-market
may be an almost essential condition of a satisfactory propensity to consume; and
this circumstance, generally overlooked until lately, obviously serves to aggravate
still further the depressing effect of a decline in the marginal efficiency of capital"
(JMK 7: 319). In today's context, adding property prices and mortgage finance
does not diminish the importance of such concerns, but enhances them."

Observa-se, deste modo, que a eficácia da PM irá depender das decisões dos agentes, sistema bancário e firmas, em relação à utilização dos recursos excedentes e segundo CARVALHO (1994:50):

\begin{abstract}
Se esses dois grupos operam em sintonia, a ação do Banco Central far-se-á sentir, por um lado, na disponibilidade de crédito de curto prazo, oferecido diretamente pelos bancos às firmas, permitindo a estas a compra do capital circulante necessário à produção; por outro lado, por mecanismos mais complexos e indiretos, através da acomodação de portfólio, primeiro de instituições financeiras e depois das firmas investidoras, afetar-se-á a aquisição de bens de investimento, com impactos sobre a geração de renda e emprego.
\end{abstract}

No entanto, estes canais podem não funcionar quando a economia se encontra em recessão. Tal fato se deve, no caso das políticas de reservas, ao que pese o aumento das disponibilidades bancárias, dependerem da preferência pela preferência pela liquidez dos bancos e das decisões empresariais de produção, que são influenciadas pelas expectativas em relação à demanda. Como neste período a demanda tende a reduzir, as empresas não irão expandir a capacidade instalada, tornando esta PM sem efeito. De modo complementar, neste período, e muito mais provável que a taxa de juros de curto prazo não consiga produzir, através de problemas de arbitragem na curva de rendimentos, reduções nas taxas de juros de longo prazo (CARVALHO, 1994:36).

De modo complementar, em períodos de crise econômica, pode prevalecer o "animal spirits", no qual os indivíduos agem de forma irracional e motivada por fatores não econômicos. Como decorrência, reduções na taxa de juros não exercerão nenhum impacto sobre a atividade econômica, bem como a PM que aumente a quantidade de moeda à disposição dos bancos (redução de compulsório) não terá impacto sobre crédito. Nesta situação, na qual a PM perde completamente a sua eficácia, o instrumento que o BC dispõe é a compra direta de ativos (títulos governamentais) no mercado, sem a intermediação de instituições bancárias com vem sendo observado desde o início da crise de 2007, além da utilização de políticas fiscais anticíclicas. Segundo ARESTIS (2009:13):

Failure to recognize the importance of "animal spirits" in monetary policy can lead to wrong condusions, for under such circumstances, monetary policy can become ineffective. Witness the experience since August 2007, over which period interest rates have been reduced substantially, but have had a very feeble effect. Also, the idea that recapitalizing the banks would allow them to lend again has not worked. Once "confidence" evaporates, banks refuse to lend, however well capitalized they may happen to be. So much so that quantitative easing, whereby the government guarantees assets acquired by the central bank, may be necessary. Indeed, fullscale nationalization of the banking sector is not ruled out either.

Finalmente, ressalta-se a importância de uma análise dinâmica das relações entre a PM e a preferência pela liquidez dos bancos e das firmas, integrada ao comportamento 
cíclico de uma economia, como proposto por MINSKY (2013) no desenvolvimento da Hipótese de Fragilidade Financeira (HFF). Nesta perspectiva, PAULA (1999), ALVES e PAULA (2003) e ALVES, DYMSKI e PAULA (2008), numa abordagem estruturalista, buscam compatibilizar este debate, com o foco principal nas decisões de portfólio dos bancos, em um ambiente de incerteza não probabilística. Ademais as PM contracionistas ou expansivas não terão impacto determinístico sobre os bancos, pois estes podem operar endogenamente, em relação aos depósitos e à oferta de créditos na economia, desde que seja rentável para estas instituições (PAULA, 1999).

Deste modo, as decisões de portfólio dos bancos e das firmas podem ser compatibilizadas com a HFF, pois as posturas adotadas pelas instituições depositárias dependem do grau de incerteza e consequentemente da preferência pela liquidez enquanto que as decisões das firmas dependerão do grau de confiança nas expectativas de longo prazo, podendo sofrer alterações ao longo das fases do ciclo econômico. Durante a fase expansiva de um ciclo econômico, existe uma tendência dos bancos e das firmas tornaremse mais endividados, e tal comportamento tem impacto sobre o risco de iliquidez e solvência dessas instituições, bem como poderá gerar fortes impactos sobre o nível de atividade econômica (ALVES et al. 2008).

Tal fato decorre das firmas assumirem uma postura especulativa, reduzindo suas margens de segurança para enfrentar seus compromissos financeiros, enquanto os bancos adotam uma postura mais acomodatícia quanto à oferta de crédito, aceitando uma estratégia menos avessa ao risco (aumentando o risco de liquidez e promovendo uma maior alavancagem). Mesmo que possam existir diferentes estratégias entre os bancos (alguns mais agressivos e outros mais conservadores em relação à expansão da carteira de crédito), de modo geral, todos os bancos passam, em maior ou menor grau, a adotarem estratégias expansivas, pois isto garante a eles o seu "market share" (ALVES et al. 2008).

No entanto, a fase de desaceleração cíclica, em que as unidades econômicas exibem uma estrutura financeira fragilizada (podendo passar de unidades especulativas para Ponzi), os bancos reagirão com o aumento na preferência pela liquidez, reduzindo sua oferta de crédito (assim como sua maturidade), mantendo reservas adicionais e comprando ativos líquidos. Assim, bancos como um todo - face à deterioração da qualidade de suas carteiras de crédito - tendem a contrair a oferta de crédito, ampliando a propagação da crise, cuja profundidade depende da capacidade de uma ação anticíclica por parte das autoridades econômicas. (ALVES et al. 2008).

Neste contexto, as PM poderão impactar de várias formas sobre o sistema financeiro e a atividade econômica. Alterações na condução de políticas econômicas, como por exemplo, elevações da taxa de juros podem impactar negativamente sobre o fluxo de caixas das unidades e, consequentemente, inviabilizarem o cumprimento de suas obrigações. Dessa forma as variações nos ciclos econômicos ocorrem como consequência das dinâmicas internas da economia capitalista e do sistema de intervenção e regulação do estado (MINSKY, 2013).

Ademais, WOLFSON (1996) destaca, a partir da HFF, que PM que promovam a elevação da taxa de juros podem empurrar o sistema financeiro para uma crise gerando aumento das obrigações de pagamentos em moeda relativas a trocar receitas e ocasionando redução do valor de mercado dos ativos. Estes conduzirão para mudanças (e frequentemente mudanças súbitas) nas atitudes de banqueiros para o perigo de emprestar, ou seja, o desenvolvimento endógeno de expectativas. Como consequência, o grau do racionamento de crédito irá depender em parte da fase do ciclo econômico e o aumento do 
racionamento de crédito também contribuirá para o fim da expansão de ciclo-econômico e o começo da recessão.

\section{CONSIDERAÇÕES FINAIS}

A teoria pós-keynesiana contrapõe ao atual modelo de política monetária de um regime de metas de inflação, baseado no Novo Consenso Macroeconômico e referenciado na ideia de que a inflação é um fenômeno monetário do lado da demanda e, deste modo, deve ser combatida exclusivamente por meio de políticas monetárias. Em contraponto, identifica-se que a taxa de juros não se constitui no instrumento mais adequado para manipular a demanda agregada em virtude dos impactos indesejados que esta provoca nas decisões de investimento. Ademais, keynesianos identificam a importância da inflação de custo, resultante de variações nos componentes da oferta na qual a taxa de juros tem baixa efetividade, atuando sobre a consequência ao invés da causa.

Ressalta-se ainda, que a transmissão da política monetária na visão keynesiana se processa de forma menos mecânica, sendo fortemente influenciada pela preferência pela liquidez dos agentes, com destaque para o papel desempenhado pelo sistema bancário. Tal fato se deve à capacidade das instituições depositarias criarem moeda escritural que é amplamente aceita para a liquidação de contratos. Nesta perspectiva teórica, a incerteza fundamental e o estado de confiança importam e podem gerar racionamento de crédito, cujos efeitos são transmitidos para a economia real.

Finalmente deve-se reforçar que o regime de metas, restrito a uma meta única de estabilidade de preços, e ausência de outros objetivos para a política monetária, tais como bem-estar econômico, baixo desemprego e estabilidade financeira, bem como a ausência de coordenação com as demais políticas econômicas (fiscal, financeira, industrial etc.) pode subutiliza-la para alcançar objetivos econômicos mais amplos.

\section{BIBLIOGRAFIA}

AMADEO, E. e DUTT, A. Os keynesianos neo-ricardianos e os pós-keynesianos. In: LIMA, Gilberto T. e SICSÚ J. (org.). Macroeconomia do Emprego e da Renda. São Paulo: Ed. Manole. 2003.

ALVES A.; DYMSKI, G. and PAULA, L. Banking Strategy and Credit Expansion: a Post Keynesian Approach. Cambridge Journal of Economics, v. 32, n.3, p. 395-420, 2008.

ALVES A. e PAULA, L. Comportamento dos bancos, percepção de risco e margem de segurança no ciclo minskiano. Análise Econômica, v. 21, n. 39, p.135-162, 2003.

ARESTIS, P. e SAWYER, M. Can monetary policy affect the real economy? European Review of Economics and Finance, vol. 3, n. 2, p. 9-32, 2004a.

ARESTIS, P. e SAWYER, M. On the effectiveness of monetary policy and of fiscal policy. Review of Social Economy, vol. 62, n. 4, p. 441-463, 2004b.

ARESTIS, P. SAWYER, M. Aggregate demand, conflict and capacity in the inflationary process. Cambridge Journal of Economics, v. 29, n. 6, p. 959-974, 2005.

ARESTIS, P. e SAWYER, M. The nature and role of monetary policy when money is endogenous. Cambridge Journal of Economics, v. 30, n. 6, p. 847-860, 2006. 
ARESTIS, P. e SAWYER, M. New consensus macroeconomics and inflation targeting.

Economia e Sociedade, v. 17, número especial, p. 631-655, 2008.

ARESTIS, P.; PAULA, L. e FERRARI, F. A nova política monetária: uma análise do regime de metas de inflação no Brasil. Economia e Sociedade, v. 18, n. 1, p. 1-30, abr., 2009.

BERNANKE, B. The Great Moderation. Remarks before the Eastern Economic Association, Washington, DC, February 20, 2004.

BERNANKE, B.; GERTLER, M. Inside the Black Box: The Credit Channel of Monetary Policy Transmission. Journal of Economic Perspectives, v. 9, n. 4, p. 27-4, 1995.

BERNANKE, B.; GERTLER, M. Monetary Policy and Asset Volatility. Federal Reserve Bank of Kansas City Economic Review, v. 84, n. 4, p. 17-52, 1999.

BERNANKE, B.; GERTLER, M. Should Central Banks Respond to Movements in Asset Prices? American Economic Review, v. 91, n. 2, p. 253-257. 2001

BLANCHARD, O. Is There a Core of Usable Macroeconomics? The American Economic Review, v. 87, n. 2, p. 244-246, May 1997.

BIBOW, J. Liquidity Preference Theory Revisited - To Ditch or to Build on It? The Levy Economics Institute, Working Paper n. 427, 2005.

BIBOW, J. A Post Keynesian Perspective on the Rise of Central Bank Independence: A Dubious Success Story in Monetary Economics. Levy Economics Institute, Working Paper n. 625, 2010.

BLINDER, A. Is There a Core of Practical Macroeconomics that We Whould All Believe? The American Economic Review, v. 87, n.2, p. 240-243, May 1997.

CARVALHO, F. Da síntese neoclássica a redescoberta de Keynes. Análise Econômica, v. 6, n. 9, p. 3-21, 1988.

CARVALHO, F. Fundamentos da Escola Pós-Keynesiana: A Teoria de uma economia Monetária. In: AMADEO (org.). Ensaios sobre economia política moderna. São Paulo: Editora Marco Zero, 1989.

CARVALHO, F. Temas de política monetária keynesiana. Ensaios FEE, v. 15, n. 1, p. 33-61, 1994.

CARVALHO, F. A independência do Banco Central e a disciplina monetária: observações céticas. Revista de Economia Política, v. 15, n. 4, 1995

CARVALHO, F. Sobre a centralidade da teoria da preferência pela liquidez na macroeconomia pós-keynesiana. Ensaios FEE, v.17, n.2, p. 42-77, 1996.

CARVALHO, F. Teoria e políticas monetárias: Uma visão pessoal sobre uma relação difícil. Econômica, v. 6, n. 2, p. 315-334, 2004.

CARVALHO, F. Uma contribuição ao debate em torno da eficácia da política monetária e algumas implicações para o caso do Brasil. Revista de Economia Política, v. 25, n. 4, p. 323-336, 2005.

CARVALHO, F. Sobre a preferência pela liquidez dos bancos. In PAULA, L. e OREIRO, J. (Org.). Sistema Financeiro: Uma análise do setor bancário brasileiro. Rio de Janeiro: Campus/Elsevier, 2007. 
CARVALHO, F. Equilíbrio fiscal e política econômica keynesiana. Revista Análise Econômica, v. 26, n. 50, p. 7-25, 2008.

CARVALHO, F. Inovação financeira e regulação prudencial: da regulação de liquidez aos acordos da Basileia. In SOBREIRA R. Regulação Financeira. Ed. Atlas, 2005.

CARVALHO, F. O retorno de Keynes. Aula Magna proferida no $36^{\circ}$ Encontro Nacional de Economia. ANPEC, 2009.

CARVALHO, F. e SICSU, J. Controvérsias recentes sobre controles de capitais. In: SICSÚ, J. e FERRARI, F. Câmbio e Controle de Capitais. Rio de Janeiro: Elsevier, 2006.

CHICK, V. A Evolução do sistema bancário e a teoria da poupança, do investimento e do juro. Ensaios FEE, Porto Alegre, v. 15, n. 1, p. 9-23, 1994.

CHICK, V. "Sobre sistemas abertos". Revista da Sociedade Brasileira de Economia Política, 13: 7-26, 2003.

DAVIDSON, P. Post Keynesian Macroeconomic Theory, Edward Elgar, Aldershot. 2004.

DAVIDSON, P. Can, or should, a central bank inflation target? Journal of Post Keynesian Economics, v. 28, n. 4, p. 689-703, 2006.

DOW, S. C. Horizontalism: a critique. Cambridge Journal of Economics, v. 20, n. 4, p. 497-508, 1996.

EGGERTSSON, G.; WOODFORD, M. The Zero Bound on Interest Rates and Optimal Monetary Policy. Brookings Papers on Economic Activity, v. 34, p. 139-211, 2003.

FERRARI, F. e PAULA, L. Regime cambial, conversibilidade da conta capital e performance econômica: a experiência recente de Brasil, Rússia, Índia e China. In Ferrari F. e Sicsú J. (org.), Câmbio e Controle de capitais: avaliando a eficiência de modelos macroeconômicos. Rio de Janeiro: Campus-Elsevier, p. 184-221. 2006.

FERRARI, F. e PAULA, L. Exchange rate regime proposal for emerging countries: a Keynesian perspective. Journal of Post Keynesian Economics, v. 31, n. 2, p. 227 -248, 2008.

FONTANA, G. e VERA, A. Are long-run price stability and short-run Output stabilization all that monetary policy can aim for? Metroeconomica, v. 58, n. 2, p. 269-298, 2007.

GOODFRIEND, M. The Monetary Policy Debate since October 1979: Lessons for Theory and Practice. Federal Reserve Bank of St. Louis Review, p. 243-262, March/April 2005.

GOODFRIEND, M. How the World Achieved Consensus on Monetary Policy. Journal of Economic Perspectives, v.21, n.4, p. 47-68, 2007.

KEYNES, J. A Treatise on Money. London: MacMillan, 1971.

KEYNES, J. Teoria Geral do Emprego do Juro e da Moeda. São Paulo: Atlas, 1982.

MACCALLUM, B. Monetary policy analysis in models without money. FRB Richmond Economic Review, v.88, n.1, p.67-96, 2002.

MEYER. L. Does Money Matter? Federal Reserve Bank of St. Louis, September/October, p.1-16, 2001. 
MINSKY, H. Estabilizando uma economia instável. Osasco: Novo Século Editora. 2013.

MODENESI, A. Regimes monetários: teoria e experiência do real. São Paulo: Ed. Manole. 2005.

MODENESI, A. e PIRES C. Mecanismo de Transmissão da Política Monetária: uma abordagem micro-macro integrada. V Encontro da Associação Keynesiana Brasileira, 2012.

OREIRO, J. Economia Pós-Keynesiana: origem, programa de pesquisa, questões resolvidas e desenvolvimentos futuros. Ensaios FEE, v. 32, n. 2, p. 283-312. 2011.

PALLEY, T. Endogenous money: what it is and why it matters. Metroeconomica, v. 53, n. 2, 2002.

PALLEY. T. A Post Keynesian Framework for Monetary Policy: Why Interest Rate Operating Procedures are not enough. In GNOS, C. e ROCHON, L. P. (editor) Post-Keynesian principles of economic policy. Ed. Edward Elgar. 2005

PALLEY. T. Gattopardo economics: The crisis and the mainstream response of change that keeps things the same. Paper prepared for the conference of the National Association of Post-Graduate Centers for Economics (ANPEC) of Brazil, Porto de Galinhas, Brazil, December 12 - 16th, 2012.

PAULA, L. Dinâmica da Firma Bancária: uma abordagem não convencional. Revista Brasileira de Economia, v. 53, n. 3, p. 136-142, 1999.

PAULA, L e PIRES, M. The effects of fiscal policy after the global recession: assessing the evidences. Brazilian Journal of Political Economy, vol. 33, n. 2, p. 315-321, 2012.

SOBREIRA, R. Preferência pela liquidez e comportamento dos bancos: para uma teoria póskeynesiana da firma bancária. Dissertação de Mestrado. Niterói: UFF, 1995.

SICSÚ, J. A negação da ineficácia da política monetária: a alternativa de Keynes e dos póskeynesianos. Revista de Análise Econômica. v. 15, n. 28, p. 80-107, 1997.

SICSÚ, J. Políticas Não-Monetárias de Controle da Inflação: uma proposta pós-keynesiana. Revista de Análise Econômica, v. 21, n. 39, p.115-136, 2003.

SICSÚ, J. e FERRARI, F. Câmbio e controle de capitais: avaliando a eficácia de modelos macroeconômicos. Rio de Janeiro: Elsevier, 2006.

TAYLOR, J. Core of practical macroeconomics. The American Economic Review, v. 87, n. 2, p. 233-235, May 1997.

WOLFSON, M. H. A Post Keynesian theory of credit rationing. Journal of Post Keynesian Economics, v. 3, n.18, p. 443-470, 1996.

WRAY, R. A teoria do dinheiro de Keynes: uma avaliação após 70 anos. Revista de Economia, v. 32, n. 2, p. 43-62, 2006.

WRAY, R. Federal Reserve Bank Governance and Independence during Financial Crisis View Less. Levy Economics Institute, Research project reports, 2014.

WOODFORD, M. Convergence in Macroeconomics: Elements of the New Synthesis. American Economic Journal: Macroeconomics, v.2, n.1, p. 267-279, 2009. 